\title{
Selectivity and competitive interactions between two benthic invertebrate grazers (Asellus aquaticus and Potamopyrgus antipodarum): an experimental study using ${ }^{13} \mathrm{C}$ - and ${ }^{15} \mathrm{~N}$-labelled diatoms
}

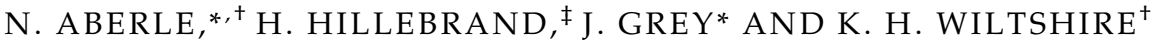 \\ *Max-Planck-Institute for Limnology, Plön, Germany \\ ${ }^{\dagger}$ Biologische Anstalt Helgoland, Stiftung Alfred-Wegener Institut für Polar- und Meeresforschung, Helgoland, Germany \\ ${ }^{\ddagger}$ Institute for Botany, Köln, Germany
}

\section{SUMMARY}

1. Tracer experiments with two diatoms labelled with ${ }^{13} \mathrm{C}$ (Nitzschia palea) and ${ }^{15} \mathrm{~N}$ (Fragilaria crotonensis), were conducted to investigate feeding selectivity and interspecific competition between the grazers Asellus aquaticus (Isopoda, Crustacea) and Potamopyrgus antipodarum (Hydrobiidae, Gastropoda). Conventional methods, such as cell counts and estimated biovolume, were used first to detect feeding preferences within the different grazer treatments.

2. The results revealed a significant decline in algal biovolume in all grazer treatments and no indications of active selectivity were observed. In contrast to conventional methods, measurements based on isotope signatures showed strong differences in tracer uptake, thus indicating different degrees of assimilation and digestion by the two grazers. 3. The selectivity index $\mathrm{Q}$, which provides information on the uptake ratio of ${ }^{13} \mathrm{C}$ to ${ }^{15} \mathrm{~N}$, showed a significant time effect for both grazer species and a significant difference between single- and mixed-grazer treatments for $P$. antipodarum. Thus, this technique enabled the direct quantification of the uptake by grazers and, therefore, served as an ideal tool for the detection of passive selectivity.

4. Our results indicate a shift in feeding preferences related to between-species competition and a potential divergence of trophic niches when species coexist.

Keywords: benthic microalgae, herbivore grazing, interspecific competition, isotope fractionation, resource partitioning

\section{Introduction}

Benthic microalgae contribute significantly to the primary production of shallow aquatic systems and are an ideal diet for small grazing animals (protists, meio- and macrofauna). The diverse literature on benthic grazing deals mainly with the importance of herbivory in benthic food-webs. Most studies have concentrated on the possible effects of grazing on algal cell numbers,

Correspondence: N. Aberle, IFM-GEOMAR, Leibniz Institute of Marine Sciences, Düsternbrooker Weg 20, 24105 Kiel, Germany. E-mail: naberle@ifm-geomar.de biomass and chlorophyll $a$ (Feminella \& Hawkins, 1995; Steinman, 1996; Hillebrand et al., 2002) and indicate a strong, direct impact of benthic grazers on periphyton biomass, which often correlates with grazer density, specific grazer types and feeding morphology (Lodge, 1986; Underwood \& Thomas, 1990; Sommer, 1997; Chase, Wilson \& Richards, 2001). Furthermore, the degree of digestion and the survival of gut passage by some microalgal species are factors that can also influence grazer-microalgae interactions, although this aspect of assimilation has been relatively neglected (Porter, 1973; Moore, 1975; Underwood \& Thomas, 1990). 
In the wake of the complexity demonstrated in the literature, studies on selectivity and feeding preferences in grazer-prey interactions in aquatic systems are becoming more important (Feminella \& Hawkins, 1995; Steinman, 1996; Chase et al., 2001; Hillebrand et al., 2002). We in general distinguish between active selectivity (active choice of food components based on prey morphology or size) and passive feeding preferences (depending on differential food uptake, assimilation or digestibility). The majority of evidence suggests a predominance of passive feeding preferences in grazer-periphyton interactions (Steinman, 1996; Hillebrand et al., 2002). If grazers have differing assimilation efficiencies for different diatom species, then periphyton community structure could affect benthic grazer communities because different food sources have different qualities. However, active selection or differential feeding may also be the primary mechanism enabling coexistence among grazer species that share resources. For example, differentiation in food particles between coexisting snail species is a classical example of reduced niche overlap between competing species (Fenchel, 1975).

Stable isotope techniques are being used increasingly to investigate food web structure in aquatic ecosystems (Peterson \& Fry, 1987; Fry, 1988). The natural stable isotope signature of a consumer generally reflects the isotopic composition of its diet in a relatively dependable manner (De Niro \& Epstein, 1981; Post, 2002). Experimentally labelling materials with stable isotopes increases their potential as tracers and provides more information on flux processes or feeding habits. For example, ${ }^{13} \mathrm{C}$-labelling has been used successfully to quantify the uptake and incorporation of tracer carbon into body tissues (Levin et al., 1999; Middelburg et al., 2000; Aberle \& Witte, 2003) and Herman et al. (2000) used a dual labelling approach wherein pelagic algae were enriched with ${ }^{15} \mathrm{~N}$ and benthic algae with ${ }^{13} \mathrm{C}$. Our objective was to investigate grazing in two co-existing herbivores with different feeding mechanisms and food particle size ranges, using stable isotope-labelled food. Furthermore, we aimed to assess differences in food selection in treatments with one or both species. Both the isopod Asellus aquaticus (Linné) and the gastropod Potamopyrgus antipodarum (E. A. Smith) are abundant herbivores in the littoral zones of European freshwaters and feed on a variety of microalgae species (Marcus, Sutcliffe \& Willoughby, 1978; James et al., 2000a). Therefore, they serve as model organisms for the detection of trophic relations.

\section{Methods}

\section{Experimental design}

Experiments with $P$. antipodarum (shell height: $3 \mathrm{~mm}$ ) and $A$. aquaticus (total length: 5-6 $\mathrm{mm}$ ) were conducted using four different treatments: a control treatment without grazers $(\mathrm{C})$, single-grazer treatments with either A. aquaticus or P. antipodarum (A or P), and a combined-grazer treatment (PA). Each treatment was replicated four times and the entire experimental set-up was duplicated to allow independent sampling for two different incubation times $(\mathrm{d} 1=1$ day; $\mathrm{d} 2=$ 2 days). Short-term incubations were chosen in order to detect natural feeding preferences immediately and to avoid adaptive feeding that might occur over time.

Erlenmeyer flasks $(300 \mathrm{~mL})$ served as experimental units and were filled with $100 \mathrm{~mL}$ filtered $(0.2 \mu \mathrm{m})$ and autoclaved water from Schöhsee, Germany. Each culture flask in each treatment was inoculated with a mixed, labelled algal solution containing $10 \mathrm{~mL}$ of Nitzschia palea (W. Smith, 1856) (small cells, singlecelled algae; 26000 cells $\mathrm{mL}^{-1}$ ) and $2 \mathrm{~mL}$ of Fragilaria crotonensis (Kitton, 1869) (large cells, chain-forming colonies; 61000 cells $\mathrm{mL}^{-1}$ ). The different initial volumes of algal solution ensured a comparable biovolume of each algal species in the treatments.

Prior to the experiment the invertebrates were hand-picked from samples from the Schöhsee (Plön, Germany), sorted by size class and stored overnight at $17^{\circ} \mathrm{C}$. The grazer addition followed a supplementary design whereby the grazer biomass in each treatment was constant. The number of individuals added to each experimental unit was calculated from their individual dry weights: eight $A$. aquaticus ( $5.6 \mathrm{mg}$ total dry weight) in treatment $\mathrm{A} ; 10$ P. antipodarum $(6.0 \mathrm{mg}$ total dry weight) in treatment $P$; while the mixedgrazer units (PA) contained four A. aquaticus and five P. antipodarum (5.8 $\mathrm{mg}$ total dry weight).

At the end of the experiment, the animals were picked live from the flasks and oven dried at $60{ }^{\circ} \mathrm{C}$ for $24 \mathrm{~h}$. Snail body tissues were removed from their shells after treating with $1 \mathrm{M} \mathrm{HCl}$-solution. For the determination of cell numbers and biovolume, $10 \mathrm{~mL}$ of the algal suspension were transferred into brownglass bottles and fixed with Lugol's solution. To 
collect faecal pellets for the measurement of ${ }^{13} \mathrm{C}$ and ${ }^{15} \mathrm{~N}$ egested by the animals, the remaining suspension was sieved through a $100 \mu \mathrm{m}$-gauze and the sieveresidues were collected on a precombusted GF/Ffilter. The residues were checked under a binocular microscope to ensure that only faecal pellets were retained on the filters. Faecal pellet material from all four replicates of each treatment was pooled to obtain sufficient material for stable-isotope analyses (approximately $0.3-0.4 \mathrm{mg}$ ).

For the determination of algal cell numbers and biovolumes, the Lugol's-fixed samples were mixed gently and $10 \mathrm{~mL}$ of samples were transferred immediately to Utermöhl counting chambers (total volume $10 \mathrm{~mL}$ ). After settlement of the sample for $24 \mathrm{~h}$, algal cells were counted under an inverted microscope and converted to biovolume following the methods of Hillebrand et al. (1999). Grazing rate was calculated separately for each diatom species, based on differences in their biovolume. The implication of this method is that each herbivore has two different feeding rates, one for each diatom taxon. Grazing rate per hour was calculated from the difference between the gross growth rate $\mu=\left(\ln V_{\mathrm{c}}-\ln V_{0}\right) \times h^{-1}$ and the net growth rate $r=\left(\ln V_{\mathrm{gr}}-V_{0}\right) \times h^{-1}$ $\left(V_{\mathrm{c}}=\right.$ biovolume of controls; $V_{0}=$ biovolume at start; $V_{\mathrm{gr}}=$ biovolume of grazer treatments all at the end of the experiment).

\section{Stable isotope labelling}

Prior to the experiment, the diatoms F. crotonensis and $N$. palea were cultured at $17{ }^{\circ} \mathrm{C}$ in artificial freshwater amended with WC medium (Guillard \& Lorenzen, 1972). The axenic F. crotonensis cultures contained $30 \% \mathrm{NaH}^{13} \mathrm{CO}_{2}$ (99 atom\%; Chemotrade Leipzig), whereas $30 \% \quad \mathrm{Na}^{15} \mathrm{NO}_{3}$ (95 atom\%; Chemotrade Leipzig) was added to the cultures of N. palea. The algae were cultivated in $500 \mathrm{~mL}$ Erlenmeyer flasks under a $16 \mathrm{~h}$ light: $8 \mathrm{~h}$ dark regime for 4 weeks.

\section{Stable isotope analyses}

Individual $A$. aquaticus were weighed into tin cups, whereas two or three individual $P$. antipodarum were pooled to obtain sufficient mass of nitrogen for analyses. Tin cups were oxidised in a Carlo Erba NA 1500 elemental analyser (Carlo Erba Instrumentazione, Milan, Italy) coupled to a Micromass IsoPrime continuous flow isotope ratio mass spectrometer (Micromass, Manchester, U.K.). Isotope ratios are expressed using the standard delta notation $\left(\delta^{13} \mathrm{C}\right.$, $\left.\delta^{15} \mathrm{~N}\right)$ in units per mil (\%o). The reference materials used were atmospheric nitrogen and, for carbon, a secondary standard of known relation to the international standard of Vienna Pee Dee belemnite. Repeat analyses of an internal standard resulted in typical precision and accuracy of $<0.2 \%$ for $\delta^{13} \mathrm{C}$ and $<0.4 \%$ for $\delta^{15} \mathrm{~N}$. Uptake of ${ }^{13} \mathrm{C}$ (and similarly ${ }^{15} \mathrm{~N}$ ) by the herbivores was calculated as excess above background and is expressed as specific uptake $\Delta \delta^{13} \mathrm{C}\left(\Delta \delta^{13} \mathrm{C}=\right.$ $\delta^{13} C_{\text {sample }}-\delta^{13} C_{\text {background }}$ ). Thus, prior to the labelling experiment, background (natural abundance) isotope signatures of each grazer species obtained directly from Schöhsee, were measured to substitute into the calculation of specific uptake. A selectivity index (Q) was defined as the quotient $\Delta \delta^{13} \mathrm{C} / \Delta \delta^{15} \mathrm{~N}$, which expresses the relative uptake of ${ }^{13} \mathrm{C}$ compared with the uptake of ${ }^{15} \mathrm{~N}$.

\section{Statistical analyses}

To test for a significant impact of herbivores on algal biomass a full-factorial ANOVA was used. Independent factors comprised time $(\mathrm{d} 1, \mathrm{~d} 2)$ and treatment $(\mathrm{C}, \mathrm{P}, \mathrm{A}$, $\mathrm{PA}$ ). Values for algal biomass were log-transformed to reduce the observed heterogeneity in variance. The uptakes of both grazers were analysed separately using a full-factorial ANOVA with the dependent variables ${ }^{13} \mathrm{C}$ - or ${ }^{15} \mathrm{~N}$-uptake and the independent factors time (d1, d2) and species combination (single, mixed). No transformation was necessary for the ${ }^{13} \mathrm{C}$ - and ${ }^{15} \mathrm{~N}$-uptake data as the variances showed no significant deviation from homogeneity. We tested for a relationship between the biomass-specific grazing rate and ${ }^{13} \mathrm{C}$ - and ${ }^{15} \mathrm{~N}$-uptake using linear regression analysis. In addition, an ANOVA on selectivity was performed using the untransformed dependent variable $Q$ $\left({ }^{13} \mathrm{C} /{ }^{15} \mathrm{~N}\right)$ and the independent factors time $(\mathrm{d} 1, \mathrm{~d} 2)$ and species combination (single, mixed). As for ${ }^{13} \mathrm{C}$ and ${ }^{15} \mathrm{~N}$-uptake both grazers were analysed separately.

\section{Results}

Algal biovolume

Both grazers reduced the biovolume of the two algal species significantly throughout the incubation 
Table 1 Grazing on N. palea $+F$. crotonensis. Results of a full factorial ANOVA for total algal biovolume, with time (d1, d2) and treatment $(\mathrm{C}, \mathrm{P}, \mathrm{A}, \mathrm{PA})$ as independent factors and total biovolume as dependent variable.

\begin{tabular}{lccrc}
\hline & d.f. & MS & F-ratio & $P$-level \\
\hline Grazer effect on N. palea & & & & \\
$\quad$ Time & 1 & 0.0172 & 0.23 & 0.6346 \\
Treatment & 3 & 1.8085 & 24.38 & 0.0000 \\
Time $\times$ treatment & 3 & 0.1323 & 1.78 & 0.1771 \\
Error & 24 & 0.0742 & & \\
Grazer effect on F. crotonensis & & & \\
$\quad$ Time & 1 & 0.1924 & 1.245 & 0.2755 \\
Treatment & 3 & 2.0684 & 13.382 & 0.0000 \\
Time $\times$ treatment & 3 & 0.0976 & 0.631 & 0.6020 \\
Error & 24 & 0.1546 & & \\
\hline
\end{tabular}

(Table 1). The biovolume of $F$. crotonensis increased in the controls, but showed a significant decline in all grazer treatments (Fig. 1a; $P<0.001$; Table 1). Grazer presence reduced the biovolume of $F$. crotonensis by $74-95 \%$. Although the mean decline in biovolume was greatest in the treatments containing only A. aquaticus (A), a significant difference between grazer species and treatments was not detected. Grazing rates on $F$. crotonensis ranged from 0.04 ( $P$. antipodarum as single-grazer, day 2) to $0.09 \mu \mathrm{m}^{3}$ biovolume $\mathrm{h}^{-1}$ (A. aquaticus as single-grazer, day 1). A significant grazer effect was detected for the reduction in biovolume of $N$. palea (Fig. 1b; $P<0.001$; Table 1) in the single- and the mixed-grazer treatments (78-95\%). Again, there was no significant difference between grazer species. The biovolume of $N$. palea in the control treatments increased from day 1 to day 2 . The hourly grazing rates for $N$. palea ranged from 0.04 (A. aquaticus as single-grazer, day 2) to $0.10 \mu \mathrm{m}^{3}$ biovolume $\mathrm{h}^{-1}$ (P. antipodarum as single-grazer, day 1 ).

\section{Isotope signatures of cultured algae}

At the beginning of the in situ labelling experiment the isotope signatures of the labelled cultures showed isotope signatures of $30.4 \%\left(\delta^{13} \mathrm{C}\right)$ and $-15.4 \%\left(\delta^{15} \mathrm{~N}\right)$ for $F$. crotonensis while $N$. palea cultures showed values of $19.6 \%\left(\delta^{13} \mathrm{C}\right)$ and $488.8 \%\left(\delta^{15} \mathrm{~N}\right)$. The background isotope signatures of unlabelled algae were $-22.5 \%$ $\left(\delta^{13} \mathrm{C}\right)$ and $-15.9 \%\left(\delta^{15} \mathrm{~N}\right)$ for $F$. crotonensis and $-19.4 \%\left(\delta^{13} \mathrm{C}\right)$ and $-7.7 \%\left(\delta^{15} \mathrm{~N}\right)$ for $N$. palea.

\section{Background isotope signatures of invertebrates}

The two grazer species taken from the Schöhsee showed similar natural isotope compositions. $\delta^{13} \mathrm{C}$ values of $P$. antipodarum were slightly higher (mean $-21.5 \pm 1.3 \%$ ) than those of A. aquaticus $(-23.6 \pm$ $0.1 \%$ ). Mean $\delta^{15} \mathrm{~N}$ values of both species were isotopically identical ( $P$. antipodarum $4.4 \pm 0.4 \% ;$ A aquaticus $4.3 \pm 0.1 \%$ ).

Uptake of ${ }^{13} \mathrm{C}$ and ${ }^{15} \mathrm{~N}$

The $\Delta \delta^{13} \mathrm{C}$ of $P$. antipodarum and A. aquaticus showed no significant variations over time and between species combination (Fig. 2a; Table 2a). Both grazers showed clear ${ }^{13} \mathrm{C}$-enrichments, with $\Delta \delta^{13} \mathrm{C}$-values converging towards the isotopic composition of the (a)

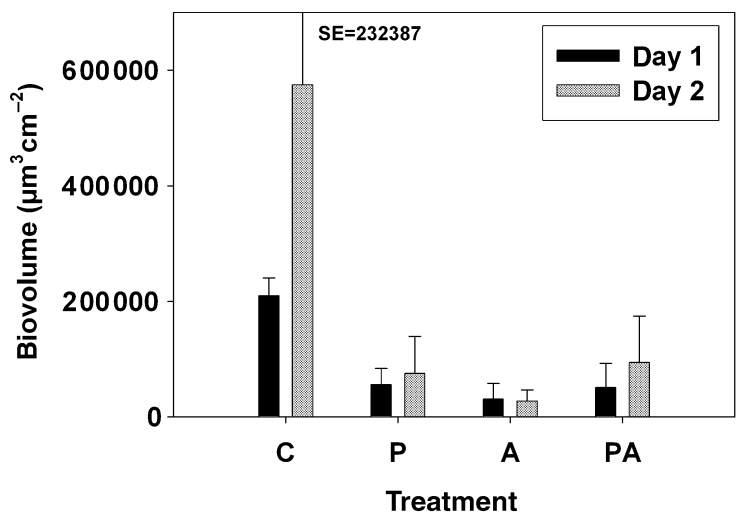

(b)

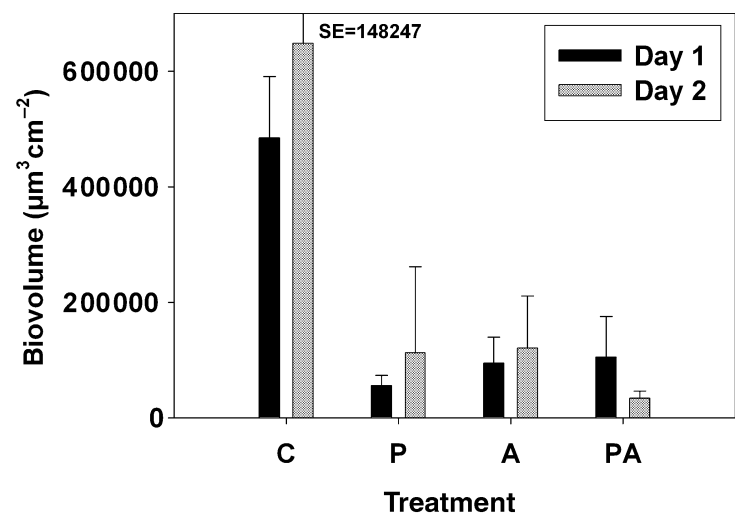

Fig. 1 Biovolume (mean $\pm \mathrm{SD}$ ) of (a) F. crotonensis and (b) N. palea in control (C), single-grazer with P. antipodarum (P) and A. aquaticus (A), and mixed-grazer treatments (PA) on day 1 and day 2 of incubation. 
(a)

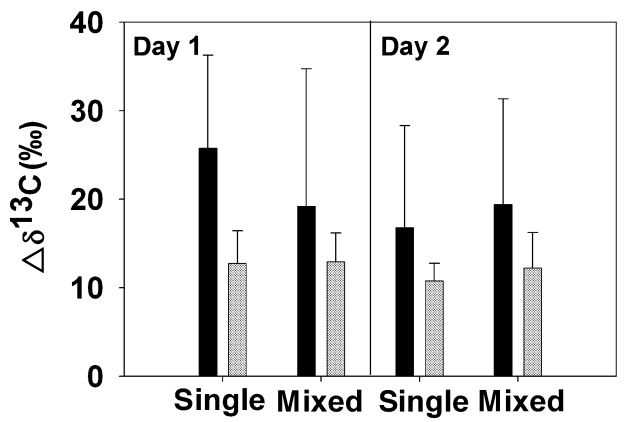

(b)

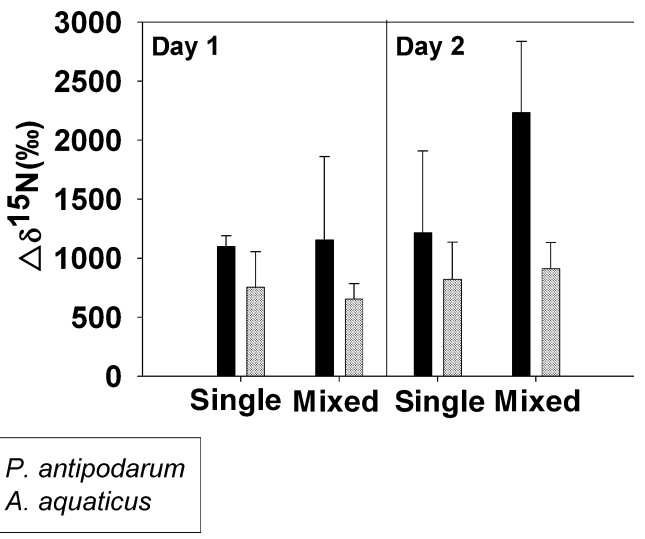

Fig. 2 (a) $\Delta \delta^{13} \mathrm{C}$ (mean $\pm \mathrm{SD}$ ) and (b) $\Delta \delta^{15} \mathrm{~N}$ (mean $\pm \mathrm{SD}$ ) of $P$. antipodarum and A. aquaticus in the single- and mixed-grazer treatments after one day (1) and after the second day (2) of incubation.

Table $2{ }^{13} \mathrm{C}$ and ${ }^{15} \mathrm{~N}$-uptake by (a) P. antipodarum and (b) A. aquaticus. Results of a full factorial ANOva for tracer uptake, with time (d1, d2) and species combination (single, mixed) as independent factors and total ${ }^{13} \mathrm{C}$ - or ${ }^{15} \mathrm{~N}$-uptake as dependent variables.

\begin{tabular}{|c|c|c|c|c|}
\hline & d.f. & MS & $F$-ratio & $P$-level \\
\hline \multicolumn{5}{|l|}{ (a) P. antipodarum } \\
\hline \multicolumn{5}{|l|}{${ }^{13}$ C-uptake } \\
\hline Time & 1 & 52.45 & 0.2566 & 0.6143 \\
\hline Species combination & 1 & 112.62 & 0.5511 & 0.4608 \\
\hline $\begin{array}{l}\text { Time } \times \text { species } \\
\text { combination }\end{array}$ & 1 & 305.83 & 1.4965 & 0.2261 \\
\hline Error & 59 & 204.36 & & \\
\hline \multicolumn{5}{|l|}{${ }^{15} \mathrm{~N}$-uptake } \\
\hline Time & 1 & 5653242 & 10.6219 & 0.0019 \\
\hline Species combination & 1 & 2967770 & 5.5762 & 0.0215 \\
\hline $\begin{array}{l}\text { Time } \times \text { species } \\
\text { combination }\end{array}$ & 1 & 3257087 & 6.1197 & 0.0162 \\
\hline Error & 59 & 532226 & & \\
\hline \multicolumn{5}{|l|}{ (b) A. aquaticus } \\
\hline \multicolumn{5}{|l|}{${ }^{13}$ C-uptake } \\
\hline Time & 1 & 34.76 & 0.5018 & 0.4805 \\
\hline Species combination & 1 & 14.12 & 0.2037 & 0.6528 \\
\hline $\begin{array}{l}\text { Time } \times \text { species } \\
\text { combination }\end{array}$ & 1 & 6.94 & 0.1002 & 0.7524 \\
\hline Error & 90 & 69.28 & & \\
\hline \multicolumn{5}{|l|}{${ }^{15} \mathrm{~N}$-uptake } \\
\hline Time & 1 & 613793 & 2.8626 & 0.0941 \\
\hline Species combination & 1 & 2226 & 0.0104 & 0.9191 \\
\hline $\begin{array}{l}\text { Time } \times \text { species } \\
\text { combination }\end{array}$ & 1 & 160563 & 0.7488 & 0.3891 \\
\hline Error & 90 & 214421 & & \\
\hline
\end{tabular}

F. crotonensis-cultures. Mean specific uptake of $N$. palea led to ${ }^{15} \mathrm{~N}$-enrichment of both grazers (Fig. 2b). $\Delta \delta^{15} \mathrm{~N}$-values of $P$. antipodarum showed that there was a significant effect of time $(P=$ $0.0019)$, species combination $(P=0.022)$, as well for the interaction between these factors $(P=0.016$, Table $2 \mathrm{~b}$ ). Potamopyrgus antipodarum alone showed lower $\Delta \delta^{15} \mathrm{~N}$-values than in the mixed-grazer treatments both on the first and on the second day of the incubation. The $\Delta \delta^{15} \mathrm{~N}$-uptakes of $P$. antipodarum showed an increase from day 1 to day 2. No significant variations over time and between singleand mixed-grazer treatments were detected for the $\Delta \delta^{15} \mathrm{~N}$-values of $A$. aquaticus (Table 2b). In general, both grazers exhibited $\delta^{15} \mathrm{~N}$ values approximately two to four times higher relative to the ${ }^{15} \mathrm{~N}$-labelled $N$. palea-cultures. No clear correlation was found between biomass-specific grazing rates and stable isotope-uptake, either for different treatments or for incubation time. The only positive correlation was on day 1: between ${ }^{13} \mathrm{C}$-uptake and the biomass-specific grazing rate $(P=0.049)$. However, this relationship disappeared on day 2.

\section{Faecal pellets}

Stable isotope analyses of faecal material revealed distinctive signatures for $P$. antipodarum pellets; the degree of ${ }^{15} \mathrm{~N}$-enrichment on days 1 and 2 was greater than the degree of ${ }^{13} \mathrm{C}$-enrichment (Fig. 3). Faecal pellets of $A$. aquaticus were also ${ }^{15} \mathrm{~N}$ - and ${ }^{13} \mathrm{C}$-enriched, but to a lesser extent than those of P. antipodarum, especially in terms of ${ }^{13} \mathrm{C}$. Pellets measured from the mixed-grazer treatments showed similar ${ }^{15} \mathrm{~N}$ - and ${ }^{13} \mathrm{C}$-enrichments to faecal pellets of $A$. aquaticus. 


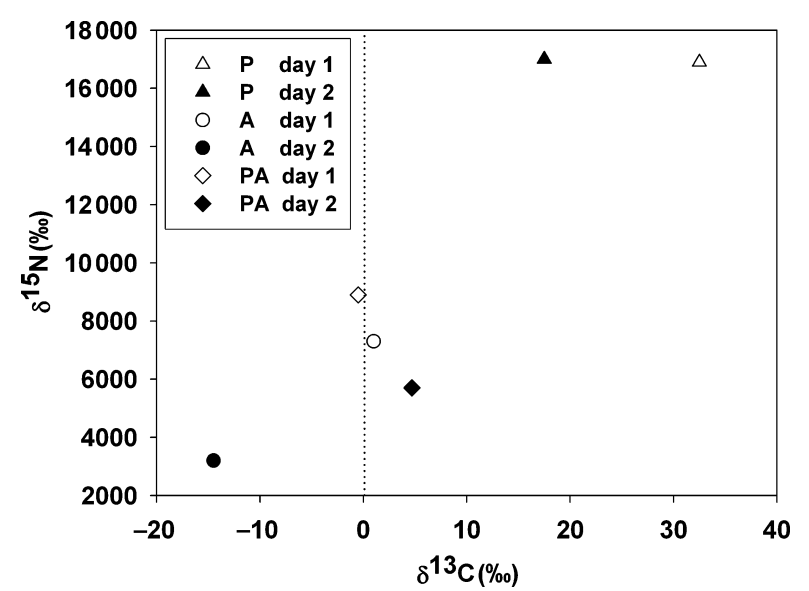

Fig. $3 \delta^{13} \mathrm{C}$ and $\delta^{15} \mathrm{~N}$ of faecal pellets (single measurements) in single-grazer (P and $\mathrm{A}$ ) and mixed-grazer treatments (PA) on the first (day 1) and the second day (day 2) of incubation.

\section{Selectivity $Q$}

The selectivity index $Q\left(\Delta \delta^{13} C / \Delta \delta^{15} N\right)$ varied significantly over time and between single- and mixedspecies treatments (Fig. 4; Table 3). Both grazers showed a significant decline in $\mathrm{Q}$ between day 1 and day 2 (A. aquaticus $P=0.0013 ; P$. antipodarum $P=0.034)$. Thus, a significant change in feeding preferences from day 1 to day 2 was detected for both species, with a higher uptake of $F$. crotonensis at the beginning of the experiment. Differences in selectivity between the single- and mixed-grazer treatments of A. aquaticus were not detected (Fig. 4; Table 3). In contrast, the Q-values for P. antipodarum

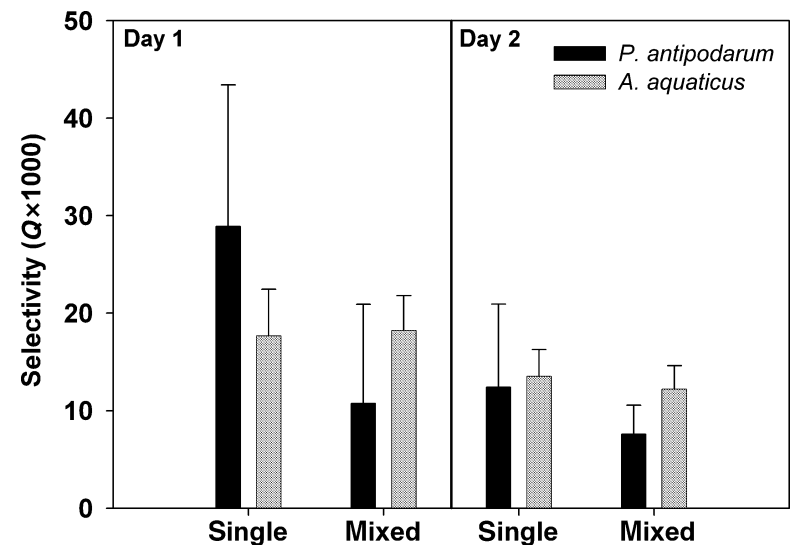

Fig. 4 Selectivity index $\mathrm{Q}\left[\left(\Delta \delta^{13} \mathrm{C} / \Delta \delta^{15} \mathrm{~N}\right) \times 1000\right]$ of $P$. antipodarum and A. aquaticus in single-grazer ( $\mathrm{P}$ and $\mathrm{A}$ ) and mixedgrazer treatments (PA) on the first (day 1) and the second day (day 2 ) of incubation (mean $\pm \mathrm{SD}$ ).
Table 3 Selectivity Q. Results of a full-factorial ANOvA for selectivity with time (d1, d2) and species combination (single, mixed) as independent factors and $\mathrm{Q}\left(\Delta \delta^{13} \mathrm{C} / \Delta \delta^{15} \mathrm{~N}\right)$ as dependent variable.

\begin{tabular}{lrlll}
\hline & d.f. & MS & F-ratio & $P$-level \\
\hline Q for A. aquaticus & & & & \\
$\quad$ Time & 1 & 0.3951 & 10.95 & 0.0013 \\
$\quad$ Species combination & 1 & 0.0179 & 0.495 & 0.4834 \\
Time $\times$ species combination & 1 & 0.0092 & 0.256 & 0.6144 \\
$\quad$ Error & 90 & 0.0361 & & \\
Q for $P$. antipodarum & & & & \\
$\quad$ Time & 1 & 0.464 & 4.71 & 0.034 \\
Species combination & 1 & 0.890 & 9.08 & 0.0039 \\
$\quad$ Time $\times$ species combination & 1 & 0.0041 & 0.042 & 0.837 \\
$\quad$ Error & 53 & 0.0985 & & \\
\hline
\end{tabular}

differed significantly between the single- and mixedgrazer treatments $(P=0.0039$; Fig. 4 ; Table 3). After the first day of incubation, $P$. antipodarum alone had Q-values two times higher than those of snails in mixed-grazer treatments.

\section{Discussion}

By using differential labelling of algal food with stable isotopes, we were able to detect differences in active and passive selectivity of two co-occurring species. Active choice of food items as a result of morphological or size-dependent features of algal prey was not observed. In contrast, passive feeding preferences detected as the uptake of stable isotopes via mechanisms such as food intake, assimilation and digestion were shown. Such an outcome would have been difficult to observe with traditional methods.

\section{Algal biovolume}

A decrease in biovolume of microphytobenthic or epiphytic communities in the presence of invertebrate grazers is a well-known phenomenon that has been detected in numerous studies (Feminella \& Hawkins, 1995; Steinman, 1996; Hillebrand et al., 2002). In addition to detritus it is assumed that the $\operatorname{diet}$ of A. aquaticus and $P$. antipodarum consists largely of diatoms, and both grazers are known to show selectivity patterns for different algal taxa (Moore, 1975; Marcus et al., 1978; James et al., 2000a). The two grazer species consumed both microalgal species in our experimental set-up, indicating that they were both suitable food sources. No biovolume differences in the consumption of algae

(C) 2005 Blackwell Publishing Ltd, Freshwater Biology, 50, 369-379 
were found between the grazer species, or over time. The main reason for a lack of significant difference between the algal biovolume consumed was the high variability among replicates. Therefore, we obtained no evidence for active selectivity.

\section{Background isotope signatures}

Diatoms had very low background $\delta^{15} \mathrm{~N}$ signatures in both the control and the ${ }^{13} \mathrm{C}$-labelled $F$. crotonensis cultures. There is limited knowledge of $\mathrm{N}$ isotope dynamics in microalgae, but several studies have shown that the nitrogen sources used, as well as culture conditions, aeration, mechanical mixing and species-specific variations, are important variables that must be considered when interpreting isotope fractionation (Needoba et al., 2003). Background isotope signatures of both grazers used in our study were within the range of values reported in the literature. James et al. (2000a) observed $\delta^{13} \mathrm{C}$ values of -20.7 to $-14.2 \%$ for P. antipodarum from a New Zealand lake whereas individuals of $P$. antipodarum from Schluensee, a neighbouring lake to Schöhsee, were isotopically enriched in comparison to individuals from Schöhsee with $\delta^{13} \mathrm{C}$ of $-19.1 \%$ and $\delta^{15} \mathrm{~N}$ of $10.1 \%$ (Brendelberger, pers. comm.). Asellus aquaticus from Schluensee had $\delta^{13} \mathrm{C}$ and $\delta^{15} \mathrm{~N}$ values of -23.4 and $9.5 \%$ (Brendelberger, pers. comm.) and individuals from English lakes were depleted showing signatures of -26.5 and $8.8 \%$ (Windermere) and -26.5 and $6.0 \%$ (from Esthwaite) (Grey, unpub. data). The demonstrated variations between species from different habitats are likely to arise from the variability in the dietary signature within and between sites, as animal tissues become enriched in $\delta^{13} \mathrm{C}$ and $\delta^{15} \mathrm{~N}$ relative to the food items used (De Niro \& Epstein, 1981). The natural isotope signatures of both invertebrate species from Schöhsee appear to reflect a dependence on microalgae as a food source. Microalgae typically show $\delta^{13} \mathrm{C}$ values of $-23.3 \%$ to $-19.4 \%$ although this can be outside this range (Hecky \& Hesslein, 1995; James et al., 2000a). Other possible food sources, such as terrestrial detritus, are unlikely to be major components of their diets as they are usually more depleted in $\delta^{13} \mathrm{C}$, with signatures ranging from $-24.7 \%$ to $-27.4 \%$ (James et al., 2000a). Indeed, A. aquaticus and $P$. antipodarum both use macrophyte/epiphytecommunities in the littoral zones of lakes as habi- tats, so an overlap of trophic niches between both grazer species is likely.

Uptake of ${ }^{13} \mathrm{C}$ and ${ }^{15} \mathrm{~N}$

The $\Delta \delta^{13} \mathrm{C}$ values for both invertebrates indicated a rapid uptake of ${ }^{13} \mathrm{C}$ from the labelled $F$. crotonensis. Similarly, the uptake of ${ }^{15} \mathrm{~N}$ (N. palea) resulted in substantial ${ }^{15} \mathrm{~N}$-enrichment of the animals. It is generally agreed that ${ }^{15} \mathrm{~N}$ fractionates more strongly between trophic levels than ${ }^{13} \mathrm{C}$ (Peterson \& Fry, 1987). The fractionation of nitrogen derives from a preference for the lighter isotope during assimilation and protein synthesis as well as during excretion of endogenous nitrogen in ammonia, urea and uric acid (Macko, Lee \& Parker, 1982; Ponsard \& Averbuch, 1999). Consequently, the protein of consumers has a higher ${ }^{15} \mathrm{~N} /{ }^{14} \mathrm{~N}$ ratio than dietary protein. Thus, the accumulation of ${ }^{15} \mathrm{~N}$ we obtained for both invertebrate grazers indicates strong fractionation of nitrogen in our experiment. Because of high ${ }^{15} \mathrm{~N} /{ }^{14} \mathrm{~N}$ ratio of the $N$. palea cultures ingested, the level of enrichment greatly exceeded the trophic fractionation usually found for natural isotope studies. Stable isotope data obtained for $P$. antipodarum and A. aquaticus infer differences in ${ }^{13} \mathrm{C}$ - and ${ }^{15} \mathrm{~N}$-uptake by both invertebrates. A possible explanation for the different results obtained with tracer uptake and algal biovolume measurements might be because of different degrees of assimilation and digestion. Digestion efficiency is known to be a function of the microalgal cell wall structure, morphotype and defensive strategy that can influence digestive pathways (Moore, 1975; Underwood \& Thomas, 1990). Moore (1975) reported a very low digestive efficiency for $A$. aquaticus but could find no evidence for cell size-dependent explanations. The digestive enzymes of $A$. aquaticus appear to show low penetration of diatom cells despite a long gut evacuation time of $25 \mathrm{~h}$ (Moore, 1975). Thus, we might have expected a weak uptake and incorporation of ${ }^{13} \mathrm{C}$ and ${ }^{15} \mathrm{~N}$ from the labelled algal material by A. aquaticus in our experiment. Little is known about the assimilation efficiency of $P$. antipodarum but Rounick \& Winterbourn (1983) showed effective utilisation of epilithon by $P$. antipodarum with assimilation efficiencies of $74 \%$ and James, Hawes \& Weatherhead (2000b) reported a fast gut evacuation time $(4.5 \mathrm{~h})$ of this snail species. From our $\Delta \delta^{15} \mathrm{~N}$ and $\Delta \delta^{13} \mathrm{C}$ values we can infer that $P$. antipodarum digested 
F. crotonensis and N. palea more efficiently than A. aquaticus. Therefore, passive selectivity as a result of higher uptake efficiencies may occur between both grazer species even when active selectivity patterns are not detectable from biovolume data. The difference in digestion efficiency was even more striking with $F$. crotonensis as food, but we can only speculate whether this might be because of colony type, larger cell size or its thicker cell walls.

\section{Faecal pellets}

When the $\Delta \delta^{13} \mathrm{C}$ and $\Delta \delta^{15} \mathrm{~N}$ values for the animals are compared with the isotope composition of their faecal pellets it is apparent that ${ }^{15} \mathrm{~N}$ and ${ }^{13} \mathrm{C}$ accumulated in the faecal pellets. ${ }^{15} \mathrm{~N}$ accumulated to a much higher degree than ${ }^{13} \mathrm{C}$, as mean $\delta^{15} \mathrm{~N}$ signatures of the faecal pellets from each treatment reached values of $9800 \%$ o, whereas for ${ }^{13} \mathrm{C}$ mean values of only $7 \%$ were detected. This can be explained by the different initial labelling efficiencies of each diatom culture leading to higher amounts of the heavy isotope ${ }^{15} \mathrm{~N}$ in the $\mathrm{N}$. palea cultures. However, this does not explain why the pellets exhibited $\delta^{15} \mathrm{~N}$ signatures approximately 10-30 times higher relative to the ${ }^{15} \mathrm{~N}$-labelled $N$. palea cultures. In general, gastrointestinal assimilation is considered to be the first step in trophic fractionation (Gorokhova \& Hansson, 1999) and isotopic composition of faecal material therefore can provide valuable dietary information.

Consistent with this contention we found that strong fractionation towards the lighter isotopes took place during gastrointestinal assimilation, resulting in a substantial accumulation of the heavy isotopes ${ }^{15} \mathrm{~N}$ and ${ }^{13} \mathrm{C}$ in faecal material. Similar findings were reported by Gorokhova \& Hansson (1999) for mysid shrimps, which show enriched $\delta^{13} \mathrm{C}$ and $\delta^{15} \mathrm{~N}$ values in their faeces. However, the proportion of heavy isotopes accumulated during assimilation and protein synthesis was still higher than in natural isotope studies because of the high initial label of the algal diets. Therefore, the high degree of heavy nitrogen accumulation in the pellets probably derives from a combination of effects associated with the higher level of ${ }^{15} \mathrm{~N}$ enrichment of $N$. palea compared with ${ }^{13} \mathrm{C}$ enrichment of $F$. crotonensis, as well as to different magnitudes of kinetic isotope fractionation during chemical and biochemical reactions. The pellets of $P$. antipodarum kept alone showed the maximum ${ }^{15} \mathrm{~N}$ accumulation, whereas pellets from snails in the mixed-grazer treatments and the treatments with $A$. aquaticus as a single grazer showed much lower $\delta^{15} \mathrm{~N}$. This suggests stronger fractionation of $P$. antipodarum towards the lighter isotope than $A$. aquaticus.

Species-specific and resource-specific variability in isotope fractionation is becoming more widely recognised, but the causative factors are difficult to define (Gannes, O'Brien \& Martinez del Rio, 1997) and few experimental studies address such variation. Needoba et al. (2003) described significant differences in isotope discrimination between different algal groups and species. Studies on natural stable isotope signatures have shown that fractionation by metazoans can be rather variable or even species-specific (De Niro \& Epstein, 1981; Macko et al., 1982; Vander Zanden \& Rasmussen, 2001; Post, 2002). Possible explanations for species-specific discrimination of heavier isotopes include differences in metabolic processes (e.g. protein synthesis), gastrointestinal assimilation, and excretion (Vanderklift \& Ponsard, 2003). In addition, there may be a correlation between the level of isotope enrichment, and the $\mathrm{C}: \mathrm{N}$ ratios of diets and consumers as well as the degree of starvation (Gorokhova \& Hansson, 1999; Adams \& Sterner, 2000; Vanderklift \& Ponsard, 2003). Our results suggest that the gastropod $P$. antipodarum discriminated against ${ }^{15} \mathrm{~N}$ more strongly than the isopod $A$. aquaticus, thus providing further support that active fractionation can taken place and that these patterns can be highly species-specific (Vander Zanden \& Rasmussen, 2001; Post, 2002).

\section{Selectivity $Q$}

Interpretation of $\Delta \delta^{13} \mathrm{C}$ and $\Delta \delta^{15} \mathrm{~N}$ values requires care as isotope enrichment of the two algal species was initially very different. Making comparisons between ${ }^{13} \mathrm{C}$ - and ${ }^{15} \mathrm{~N}$-uptake is thus difficult. We cannot treat the values derived from isotope uptake as absolute values. Direct comparisons should only be made between treatments rather than between the $\delta^{13} \mathrm{C}$ and $\delta^{15} \mathrm{~N}$ values. In order to avoid inaccurate direct comparisons between $\delta^{13} \mathrm{C}$ and $\delta^{15} \mathrm{~N}$ signatures, the selectivity index $\mathrm{Q}$ was applied. The $\mathrm{Q}$ value represents a ratio between both signatures and it can be used to evaluate the relative importance of each diatom species in the diet of each grazer. The $Q$ value enables detection of relative shifts in preference and 
therefore overcomes difficulties inherent in comparing $\delta^{13} \mathrm{C}$ values directly with $\delta^{15} \mathrm{~N}$ values. Many studies have used two-end-member-mixing models to determine the relative importance of two food sources to the diet of consumers (e.g. Vander Zanden \& Rasmussen, 2001; Post, 2002). The advantage of this method is that isotope data are corrected first for fractionation, and then the actual importance of each food source can be estimated. However, an implicit assumption of the model is that the consumer is in isotopic equilibrium with its diet. Our experiment was of 2 days duration, too short a period for complete turnover of the experimental animal tissues. Moreover, gut contents were included in the analyses, thus preventing the use of such a model. We used the selectivity index $\mathrm{Q}$ although it does not incorporate a fractionation factor.

Each grazer treatment showed a significant time effect, indicating that both grazers consumed a higher percentage of $F$. crotonensis during the first day of incubation and switched to a N. palea-based diet on the second day. The shift from one food source to the other can be explained by changes in relative amounts of each alga available, and the increased effort in consuming the more firmly attached N. palea compared with F. crotonensis. As the biovolume of each algal species had already declined significantly by day 1 it seems likely that consuming the single-celled diatom N. palea (which presented a more uniform distribution within the experimental units) was a better feeding strategy than having to scavenge actively to find the few remaining colonies of $F$. crotonensis. The shift in preference from day 1 to day 2 indicates that, as long as large amounts of different algae are available, active selectivity takes place. However, as soon as food becomes limited, a rather unselective but more efficient feeding strategy is chosen. The correlation between food concentration and selectivity is a well known phenomenon in planktonic systems (Cowles, 1979; DeMott, 1995; Boenigk et al., 2002). Thus, our assumption of concentration-dependent shifts in preference can serve as a possible explanation. On the other hand the shift in preference could also be related to digestive enzyme kinetics.

Enzyme activities are known to change with food conditions and differences in food conversion efficiency or adaptability are important factors that can influence digestive pathways (Brendelberger, 1997a). Some of the enzymes used during assimilation are secreted by the animals themselves but a considerable amount originates from bacteria associated with the food sources and bacteria living in the guts and digestive glands of snails (Brendelberger, 1997a and literature cited therein). Consequently, the changing resource use of both invertebrates on the second day of the experiment could also be related to the ability of the animals to adapt their enzymatic potential to changing food sources and availabilities. In addition to the effect of time, a significant difference between single- and mixed-grazer treatments was seen for the gastropod $P$. antipodarum, which only showed a preference for $F$. crotonensis when no co-occurring grazer was present. When both invertebrates had to share food sources, $P$. antipodarum changed from a F. crotonensis-based to a N. palea-based diet; the presence of $A$. aquaticus induced a shift in resource use of $P$. antipodarum.

Many studies in community ecology have investigated the effect of coexistence on the resource use of competitors. However, intense discussion and debate regarding mechanisms that determine species coexistence with shared resources still remains (Ricklefs \& Schluter, 1993; Gaston, 2000). Studies on the coexistence of species have often produced contradictory results with respect to overlapping tropic niches and resource partitioning (Rossi, Fano \& Basset, 1983; Costantini \& Rossi, 1998), but in our study interspecific competition appeared to induce a shift in feeding preference. A possible explanation for the change in resource use by $P$. antipodarum in the presence of A. aquaticus could be related to the adaptability of its digestive enzymes. As already pointed out, enzyme activity is influenced by the food items consumed and an animals prefeeding history can influence digestive efficiency. The shift in feeding preference of $P$. antipodarum might be related to an increase in enzymatic activity in the case of coexistence. In this context the aspect of coprophagy is of special interest as several gastropods are known to use faecal pellets from different species as supplementary food sources, enabling between-species interchange of digestive enzymes (Brendelberger, 1997b). Thus, P. antipodarum may have taken up faecal material together with associated bacteria and their enzymes from the coexisting $A$. aquaticus, and the supplementary enzymes might have led to more efficient ${ }^{15} \mathrm{~N}$-uptake by $P$. antipodarum. In addition, coprophagy could well have had a strong impact on the grazer's accumula- 
tion of ${ }^{15} \mathrm{~N}$ (see also the section on 'Uptake of ${ }^{13} \mathrm{C}$ and ${ }^{15} \mathrm{~N}^{\prime}$ ). i.e. the uptake of highly enriched faecal pellets might explain the extreme accumulation of ${ }^{15} \mathrm{~N}$ by the grazers.

The changes in feeding preference that we observed were based on tracer uptake rather than algal biomass determination and provide evidence that passive selection can occur even if active selection does not. As algal biovolumes declined in the single- and mixed-grazer treatments, it is assumed that differential digestion resulted from different digestion efficiencies. Our data confirm that the actual abundance of grazed algal cells did not automatically reflect the actual amount of digested material (see also Underwood \& Thomas, 1990; Brendelberger, 1997a). Insights into grazer feeding preferences in microphytobenthic systems achieved from a new combination of stable isotope labelling, have provided us with a basis for further experiments on feeding preferences and resource partitioning.

\section{Acknowledgments}

Arne Malzahn is thanked for his patient assistance with macrozoobenthos sampling, material sorting as well as for helpful discussions. Prof. W. Lampert supported this work and provided valuable ideas. The comments of two anonymous reviewers helped us to improve the manuscript considerably. We acknowledge the funding of this work by the 'Deutsche Forschungsgemeinschaft' (DFG-Förderzeichen WI 1810/2-1 + WI 1810/2-3).

\section{References}

Aberle N. \& Witte U. (2003) Deep-sea macrofauna exposed to a simulated sedimentation event in the abyssal NE Atlantic: in situ pulse-chase experiments using ${ }^{13} \mathrm{C}$-labelled phytodetritus. Marine Ecology Progress Series, 251, 37-47.

Adams T.S. \& Sterner R.W. (2000) The effect of dietary nitrogen content on trophic level super(15)N enrichment. Limnology and Oceanography, 3, 601-607.

Boenigk J., Matz C., Juergens K. \& Arndt H. (2002) Food concentration-dependent regulation of food selectivity of interception-feeding bacterivorous nanoflagellates. Aquatic Microbial Ecology, 27, 195-202.

Brendelberger H. (1997a) Determination of digestive enzyme kinetics: a new method to define trophic niches in freshwater snails. Oecologia, 109, 34-40.
Brendelberger H. (1997b) Coprophagy: a supplementary food source for two freshwater gastropods?. Freshwater Biology, 38, 145-157.

Chase J., Wilson W. \& Richards S. (2001) Foraging tradeoffs and resource patchiness: theory and experiments with a freshwater snail community. Ecology Letters, 4, 304-312.

Costantini M.L. \& Rossi L. (1998) Competition between two aquatic detritivorous isopods: a laboratory study. Hydrobiologia, 368, 17-27.

Cowles T. (1979) The feeding response of copepods from the Peru upwelling system: a food selection. Journal of Marine Research, 37, 601-622.

De Niro M.J. \& Epstein S. (1981) Influence of diet on the distribution of nitrogen isotopes in animals. Geochemical Journal, 45, 341-352.

DeMott W.R. (1995) Food selection by calanoid copepods in response to between-lake variation in food abundance. Freshwater Biology, 33, 171-180.

Feminella J.W. \& Hawkins C.P. (1995) Interactions between stream herbivores and periphyton: a quantitative analysis of past experiments. Journal of the North American Benthological Society, 14, 465-509.

Fenchel T. (1975) Character displacement and coexistence in mud snails Hydrobiidae. Oecologia, 20, 19-32.

Fry B. (1988) Food web structure on Georges Bank northwestern Atlantic Ocean from stable carbon nitrogen and sulfur isotopic compositions. Limnology and Oceanography, 33, 1182-1190.

Gannes L., O'Brien D. \& Martinez del Rio C. (1997) Stable isotopes in animal ecology: assumptions, caveats, and a call for more laboratory experiments. Ecology, 78, 1271-1279.

Gaston K. (2000) Global patterns in biodiversity. Nature, 405, 220-227.

Gorokhova E. \& Hansson S. (1999) An experimental study on variations in stable carbon and nitrogen isotope fractionation during growth of Mysis mixta and Neomysis integer. Canadian Journal of Fisheries and Aquatic Sciences, 56, 2203-2210.

Guillard R.L. \& Lorenzen C. (1972) Yellow-green algae with chlorophyllide c. Journal of Phycology, 8, $10-14$.

Hecky R.E. \& Hesslein R.H. (1995) Contributions of benthic algae to lake food webs as revealed by stable isotope analysis. Journal of the North American Benthological Society, 14, 631-653.

Herman P., Middelburg J., Widdows J., Lucas C. \& Heip C. (2000) Stable isotopes as trophic tracers: combining field sampling and manipulative labelling of food resources for macrobenthos. Marine Ecology Progress Series, 204, 79-92. 
Hillebrand H., Duerselen C.-D., Kirschtel D., Pollingher U. \& Zohary T. (1999) Biovolume calculation for pelagic and benthic microalgae. Journal of Phycology, 35, 403-424.

Hillebrand H., Kahlert M., Haglund A., Berninger U., Nagel S. \& Wickham S. (2002) Control of microbenthic communities by grazing and nutrient supply. Ecology, 83, 2205-2219.

James M.R., Hawes I., Weatherhead M., Stanger C. \& Gibbs M. (2000a) Carbon flow in the littoral food web of an oligotrophic lake. Hydrobiologia, 441, 93-106.

James M.R., Hawes I., Weatherhead M. (2000b) Removal of settled sediments and periphyton from macrophytes by grazing invertebrates in the littoral zone of a large oligotrophic lake. Freshwater Biology, 44, 311-326.

Levin L.A., Blair N.E., Martin C.M., DeMaster D.J., Plaia G. \& Thomas C.J. (1999) Macrofaunal processing of phytodetritus at two sites on the Carolina margin: in situ experiments using ${ }^{13} \mathrm{C}$-labeled diatoms. Marine Ecology-Progress Series, 182, 37-54.

Lodge D. (1986) Selective grazing on periphyton: a determinant of freshwater gastropod microdistribution. Freshwater Biology, 16, 831-841.

Macko S.A., Lee W.Y. \& Parker P.L. (1982) Nitrogen and carbon isotope fractionation by two species of marine amphipods- laboratory and field studies. Journal of Experimental Marine Biology E Ecology, 63, 145-150.

Marcus J., Sutcliffe D. \& Willoughby L. (1978) Feeding and growth of Asellus aquaticus, Isopoda, on food items from the littoral of Windermere, England UK, including green leaves of Elodea canadensis. Freshwater Biology, 8, 505-520.

Middelburg J., Barranguet C., Boschker H., Herman P., Moens T. \& Heip C. (2000) The fate of intertidal microphytobenthos carbon: an in situ ${ }^{13} \mathrm{C}$-labeling study. Limnology \& Oceanography, 45, 1224-1234.

Moore J. (1975) The role of algae in the diet of Asellus aquaticus and Gammarus pulex. Journal of Animal Ecology, 44, 719-730.

Needoba J., Waser N., Harrison P. \& Calvert S. (2003) Nitrogen isotope fractionation in 12 species of marine phytoplankton during growth on nitrate. Marine Ecology Progress Series, 255, 81-91.
Peterson B. \& Fry B. (1987) Stable isotopes in ecosystem studies. Annual Review of Ecology and Systematics, 18, 293-320.

Ponsard S. \& Averbuch P. (1999) Should growing and adult animals fed on the same diet show different delta ${ }^{15} \mathrm{~N}$ values?. Rapid Communications in Mass Spectrometry, 13, 1305-1310.

Porter K.G. (1973) Selective grazing and differential digestion of algae by zooplankton. Nature, 244, 179-180.

Post D. (2002) Using stable isotopes to estimate trophic position: Models, methods, and assumptions. Ecology, 83, 703-718.

Ricklefs R. \& Schluter D. (1993) Species Diversity in Ecological Communities: Historical and Geographical Perspectives. University of Chicago Press, Chicago IL, U.S.A.

Rossi L., Fano E. \& Basset A. (1983) Sympatric coevolution of the trophic niche of two detritivorous isopods Asellus aquaticus and Proasellus coxalis. Oikos, 40, 208215.

Rounick J.S. \& Winterbourn M.J. (1983) The formation structure and utilization of stone surface organic layers in two New-Zealand streams. Freshwater Biology, 13, 57-72.

Sommer U. (1997) Selectivity of Idothea chelipes (Crustacea: Isopoda) grazing on benthic microalgae. Limnology and Oceanography, 42, 1622-1628.

Steinman A.D. (1996) Effects of grazers on freshwater benthic algae. In: Algal Ecology: Freshwater Benthic Ecosystems (Eds R.J. Stevenson, M.L. Bothwell \& R.L. Lowe), pp. 341-373. Academic Press, San Diego.

Underwood G.J.C. \& Thomas J.D. (1990) Grazing interactions between pulmonate snails and epiphytic algae and bacteria. Freshwater Biology, 23, 505-522.

Vander Zanden M. \& Rasmussen J. (2001) Variation in delta ${ }^{15} \mathrm{~N}$ and delta ${ }^{13} \mathrm{C}$ trophic fractionation: implications for aquatic food web studies. Limnology $\mathcal{E}$ Oceanography, 46, 2061-2066.

Vanderklift M. \& Ponsard S. (2003) Sources of variation in consumer-diet del ${ }^{15} \mathrm{~N}$ enrichment: a meta-analysis. Oecologia, 136, 169-182.

(Manuscript accepted 4 November 2004) 